\title{
Gambaran radiografi impaksi ektopik molar tiga disertai kista dentigerous dalam sinus maksilaris pada radiograf CBCT 3D
}

\author{
Nova Rosdiana ${ }^{1 *}$, Farina Pramanik ${ }^{2}$
}

\begin{abstract}
Objectives: The aim of this case report is to explain further about radiograph on impacted right surrounded by radiointermediate image in maxillary maxillary third molar and canine using CBCT 3D. sinus. The result of 3D CBCT radiograph exhibited Case Report: A 18 year old female patient came radioopaque image resembling tooth 18 surrounded with swelling on her upper right posterior gum. The condition was associated with pus contained in the gum. Physical examination revealed no exact abnormalities condition on her teeth. Panoramic radiograph examination showed radiopaque image
surrounded by radiointermediate image in maxillary
sinus. The result of $3 D C B C T$ radiograph exhibited
radioopaque image resembling tooth 18 surrounded
by unilocular radiointermediate filling $2 / 3$ maxillary sinus with well-defined border.

Conclusion: $C B C T$ is a supported examination which may help in establishing diagnosis more accurately.

Keywords: CBCT 3D, ectopic impacted third molar, dentigerous cyst, maxillary sinus

Cite this article: Rosdiana N, Pramanik F. Gambaran radiografi impaksi ektopik molar tiga disertai kista dentigerous dalam sinus maksilaris pada radiograf CBCT 3D. Jurnal Radiologi Dentomaksilofasial Indonesia 2019;3(2)11-4. https://doi.org/10.32793/jrdi.v3i2.485
\end{abstract}

\section{PENDAHULUAN}

Kista dentigerous merupakan kista posisi mesiodistal dan vertikal dari gigi impaksi. perkembangan yang paling umum ditemukan Namun, panoramik tidak dapat mengevaluasi posisi setelah kista radikuler. ${ }^{1}$ Kista dentigerous sering impaksi maupun lesi dalam arah buko-lingual. Oleh juga disebut dengan kista folikuler. Kista jenis karena itu, terkadang diperlukan pemeriksaan merupakan lesi odontogenik jinak yang umumnya lanjutan menggunakan CBCT 3D. ${ }^{12}$ CBCT $3 D$ terbentuk karena adanya akumulasi cairan antara diindikasikan ketika gigi ektopik berkaitan dengan enamel mahkota gigi dan epitel enamel yang lesi pada sinus maksilaris dan membutuhkan mengelilinginya. ${ }^{2,3}$ Kista dentigerous berkaitan pembedahan. ${ }^{13}$ CBCT $3 \mathrm{D}$ sangat membantu klinisi dengan impaksi gigi molar tiga dan kaninus dalam menentukan batas tepi jaringan keras dari maksila. ${ }^{3,4,5,6}$ Kista ini juga dapat berkaitan dengan invasi jaringan lunak lesi. Keuntungan CBCT 3D gigi supernumerari maupun ektopik. ${ }^{3}$

Gigi ektopik adalah gigi yang berlokasi bukan di lengkung rahang. ${ }^{6}$ Gigi ektopik biasanya belokasi tidak lazim jauh dari lokasi anatomi normal. Beberapa lokasi ektopik yang pernah dilaporkan adalah pada rongga hidung, dagu, sinus maksilaris, tulang mandibula, palatum, dan rongga orbita. ${ }^{6,7,8}$ Kebanyakan kasus gigi ektopik asimtomatik, namun beberapa dapat menimbulkan rasa sakit pada wajah, epitaksis, sakit kepala, pembengkakan, atau mengeluarkan pus bergantung pada lokasinya. ${ }^{8,9}$ Gigi ektopik dalam sinus maksilaris merupakan kasus yang jarang, dan biasanya ditemukan secara tidak sengaja pada pemeriksaan radiografi. ${ }^{6,8,9,10}$ Secara radiografi, kista dentigerous memperlihatkan gambaran radiolusensi unilokuler dengan tepi sklerotik berbatas jelas yang mengelilingi mahkota gigi yang impaksi. ${ }^{2,11}$

Radiografi panoramik mengambil peranan penting dalam mendeteksi gigi yang impaksi, serta melihat kondisi patologis pada rahang. Radiografi panoramik dapat menggambarkan dengan jelas adalah menyediakan reformasi multiplanar dengan rekonstruksi volume dan gambar 3D dengan dosis radiasi yang jauh lebih rendah dibadingkan dengan computed tomography (CT). CBCT 3D memungkinkan dokter secara akurat menilai luas lesi dan kedekatannya dengan stuktur vital yang berdekatan. $^{1}$

\section{LAPORAN KASUS}

Pasien perempuan berusia 18 tahun datang ke dokter gigi dengan keluhan gusi belakang kanan atas bernanah. Pemeriksaan ekstra oral tidak menunjukkan perubahan ataupun asimetri pada wajah (Gambar 1A). Keadaan umum pasien baik dan tidak ada riwayat penyakit sistemik. Pemeriksaan klinis tidak menunjukkan adanya kelainan pada gigi-gigi pada regio tersebut (Gambar 1B). Pasien dirujuk untuk pemeriksaan radiografi panoramik. Hasil radiografi panoramik menunjukkan adanya gambaran radiopak 


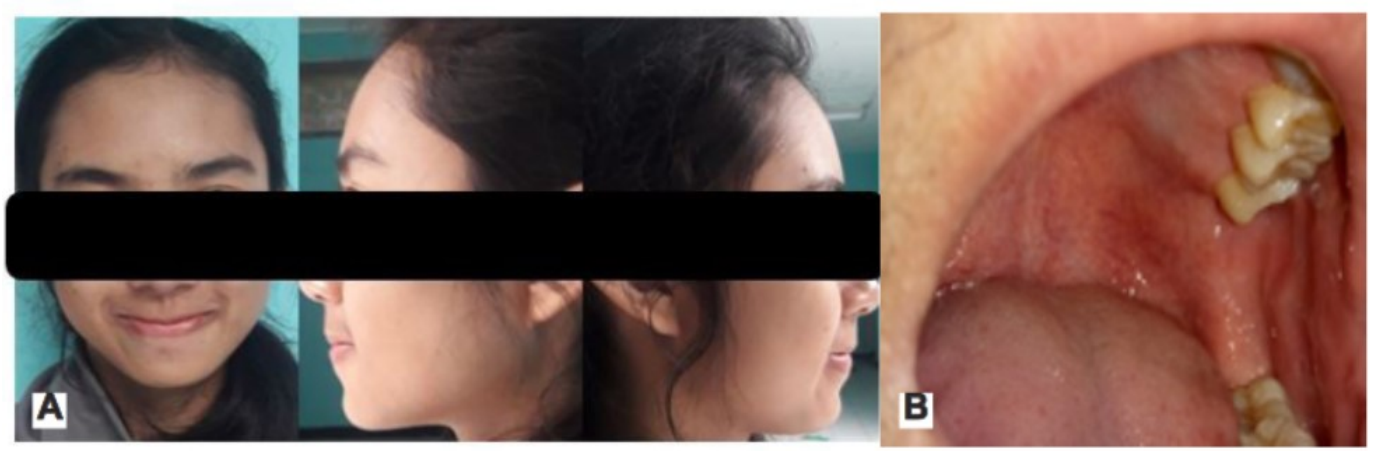

Gambar 1. Pemeriksaan klinis, (A) Keadaan ekstraoral normal tidak tampak perubahan dan asimetri pada wajah; (B) Pemeriksaan intraoral menunjukkan gigi 18 yang belum erupsi dan tidak tampak kelainan pada gigi-gigi posterior

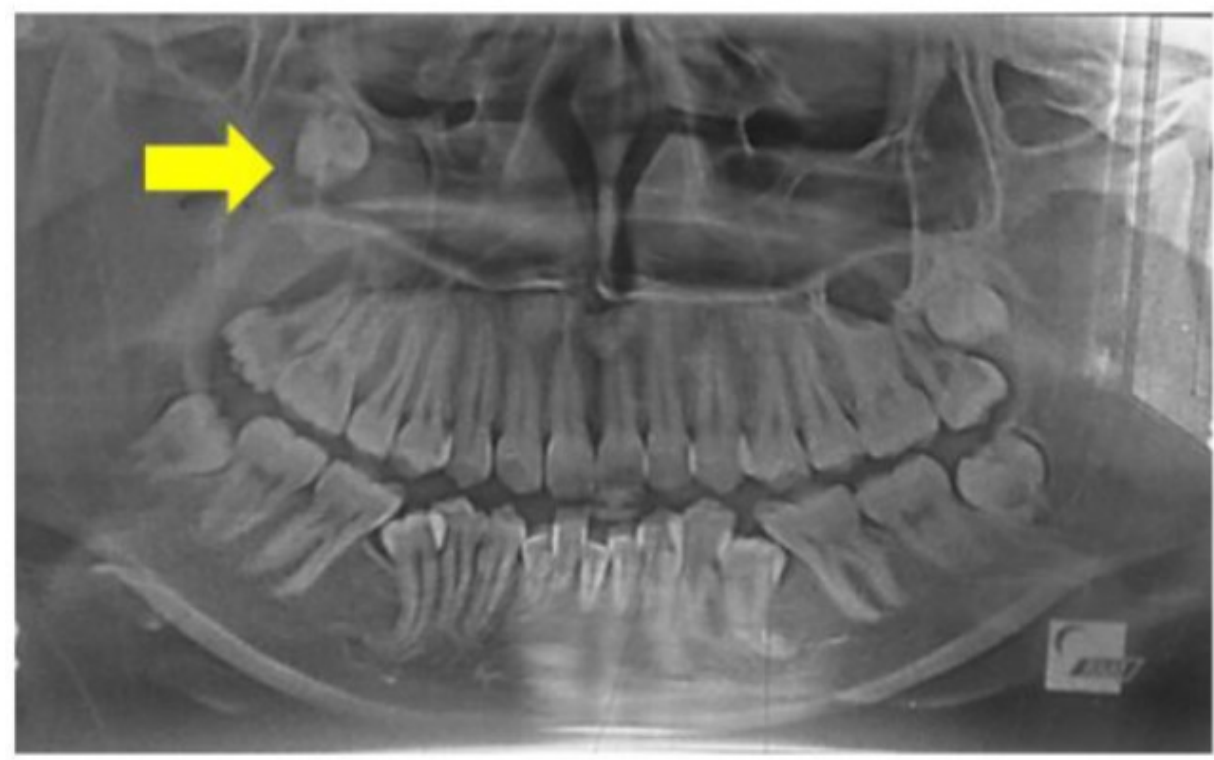

Gambar 2. Radiografi panoramik menunjukkan gambaran massa radiopak berbatas jelas dan tegas menyerupai struktur gigi pada regio sinus maksilaris kanan (panah kuning)

menyerupai benih gigi 18 dikelilingi gambaran radiointermedia di area sinus maksilaris kanan (Gambar 2). Selanjutnya pasien dirujuk untuk dilakukan pemeriksaan radiografi CBCT 3D. Hasil pemeriksaan dengan radiografi CBCT 3D menunjukkan terdapat gambaran radiopak menyerupai gigi 18 dalam gambaran radiointermedia unilokuler yang memenuhi $2 / 3$ sinus maksilaris dextra dengan batas jelas dan tegas (Gambar 3).

Kesan yang dapat disimpulkan adalah gigi impaksi 18 dengan posisi gigi masuk ke dalam sinus maksilaris dan terdapat gambaran radiointermedia dengan batas jelas dan tegas mengelilingi gig impaksi 18. Suspek radiodiagnosis gigi Impaksi 18 kelas $\mathrm{C}$ berada di dalam sinus maksilaris disertai kista dentigerous dengan diagnosa banding ameloblastoma unikistik.

\section{DISKUSI}

Gigi ektopik adalah gigi yang berlokasi terpendam bukan pada lengkung rahang, melainkan berpindah jauh dari posisi anatomi normalnya. ${ }^{3}$
Erupsi gigi ektopik biasanya terlihat dalam rongga mulut. Meskipun jarang, gigi ektopik pada area yang berbeda seperti kondilus mandibula, processus koronoid, rongga hidung, palatum, dan sinus maksilaris pernah dilaporkan., ${ }^{3,6,9}$ Etiologi dari gigi yang erupsi ektopik ini masih belum diketahui dengan pasti, namun banyak teori seperti trauma, infeksi, faktor genetik, anomali perkembangan, aktifitas iatrogenik, idopatik, dan kondisi patologis seperti kista dentigerous dapat menjadi penyebabnya. ${ }^{3,6,13}$ Kondisi ini dipercaya dapat mendorong benih gigi karena ekspansi lesi kista yang menyebabkan erupsi gigi menjadi ektopik. ${ }^{6,7}$

Kista dentigerous merupakan kista yang umum ditemukan pada rahang. Kista ini terbentuk disekitar gigi yang tidak erupsi atau gigi supernumerary. ${ }^{2}$ Sebagian besar kista dentigerous asimtomatik dan tidak aktif sampai kista tersebut mengalami infeksi. Ketika kista menimbulkan rasa sakit, atau kista membesar maka akan menyebabkan pembengkakan dan ekspansi rahang. Kista biasanya ditemukan dalam pemeriksaan radiografi rutin. Radiografi konvensional berguna dalam identifikasi adanya gigi ektopik dan menetapkan diagnosa sementara lesi. ${ }^{1,9}$ Panoramik, 
water's view, dan plain skull merupakan metode sederhana yang mudah dilakukan dalam praktik sehari-hari. Namun, teknik-teknik tersebut menampilkan gambaran dua dimensi yang sulit diinterpretasi dikarenakan banyaknya tumpang tindih dengan struktur tulang kranial lainnya. ${ }^{13}$ Teknik radiografi khusus lanjutan seperti Computed Tomography (CT) dan Cone Beam Computed Tomography (CBCT) sangat penting dalam mendiagnosa kista yang melibatkan sinus maksilaris. ${ }^{1,15}$

CBCT sangat bermanfaat dalam mendemarkasi tepi jaringan keras dari invasi jaringan lunak lesi. ${ }^{14}$ Keuntungan utama dari CBCT adalah dapat menyajikan reformasi multiplanar dengan rekonstruksi volume dan gambar 3D dengan dosis radiasi yang jauh lebih rendah bila dibandingkan dengan CT. Hal ini memungkinkan ahli bedah untuk
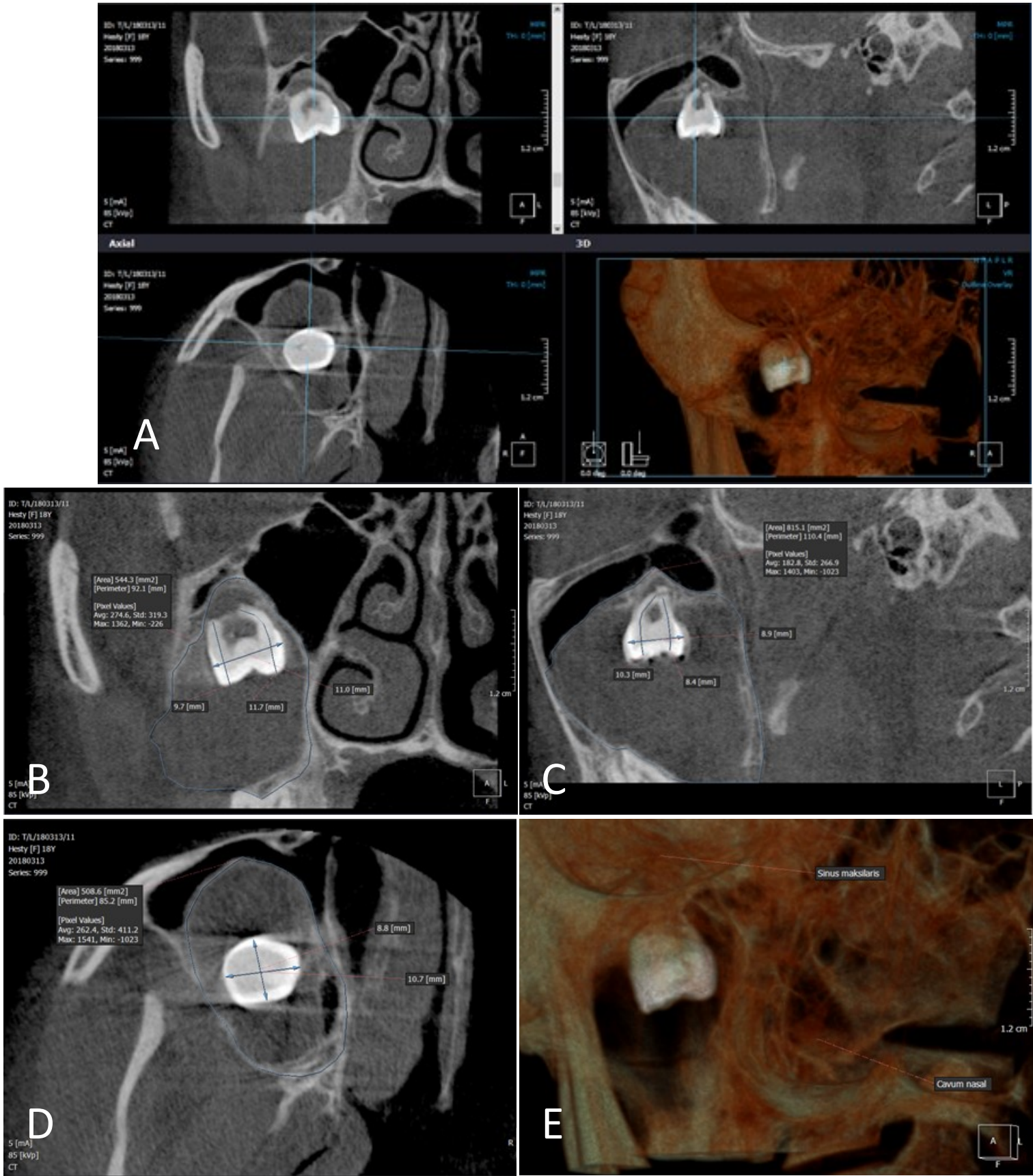

Gambar 3. Hasil pemeriksaan radiografi CBCT 3D, (A) MPR view; (B) Coronal view, memperlihatkan gigi 18 impaksi dengan ukuran lebar gigi $11 \mathrm{~mm}$, panjang gigi di akar mesial adalah $11,7 \mathrm{~mm}$ posisi akar dilaserasi ke distal, ukuran panjang gigi di akar distal adalah 9,7 mm. Gigi masuk ke dalam sinus maksilaris. Terlihat gambaran radiointermedia dengan batas jelas dan tegas yang mengelilingi gigi impaksi dengan luas area $544,3 \mathrm{~mm}^{2}$; (C) Sagittal view, memperlihatkan gigi impaksi dengan ukuran lebar gigi $8,4 \mathrm{~mm}$, panjang gigi di bukal $10,3 \mathrm{~mm}$ posisi akar dilaserasi ke distal, ukuran panjang gigi di akar distal adalah $8,9 \mathrm{~mm}$. Gigi masuk ke dalam sinus maksilaris. Terlihat gambaran radiointermedia dengan batas jelas dan tegas mengelilingi gigi impaksi 18 dengan luas area 815,1 $\mathrm{mm}^{2}$; (D) Axial view, memperlihatkan ukuran gigi adalah $10,7 \mathrm{~mm} \times 8,8 \mathrm{~mm}$. Terdapat gambaran radiointermedia mengelilingi gigi dengan ukuran luas area 508,5 $\mathrm{mm}^{2}$ dengan gigi berada di dalam sinus maksilaris; (E) 3D view gigi 18 
menilai luas lesi secara akurat serta menilai kedekatannya dengan struktur vital yang berdekatan. ${ }^{1}$

CBCT pada kasus pasien ini menujukkan adanya gigi 18 impaksi ektopik disertai kista dentigerous hingga masuk ke dalam sinus maksilaris dengan perforasi dari dasar sinus hingga mendekati dasar orbita. $^{16}$

\section{SIMPULAN}

Kista dentigerous terkait dengan gigi ektopik dalam sinus maksilaris merupakan fenomena yang jarang ditemukan. Apabila ditemukan pasien dengan kondisi gigi tidak erupsi, sebaiknya dilakukan pemeriksaan radiografi untuk identifikasi dan mencegah perkembangan lesi. CBCT merupakan salah satu teknik radiografi yang paling baik dalam menentukan perluasan lesi kista guna menentukan rencana perawatan bedah.

\section{DAFTAR PUSTAKA}

1. Mamatha NS, Krishnamoorthy B, Savitha JK, Bhai P. Diagnostic $\mathrm{CBCT}$ in dentigerous cyst with ectopic third molar in the maxillary sinus-A case report. J Clin Diagnostic Res. 2014;8 (6):9-11.

2. White S C MJP. Oral Radiology and Interpretation. 7th ed. Canada: Elsevier Inc.; 2014

3. Kara Mi, Yanık S, Altan A, Öznalçın O, Ay S. Large Dentigerous Cyst in the Maxillary Sinus Leading To Diplopia and Nasa Obstruction: Case Report. J Istanbul Univ Fac Dent [Internet] 2015;49(2):46. Available from: http://dergipark.gov.tr/ doi/10.17096/jiufd.10506

4. Kasat VO, Karjodkar FR, Laddha RS. Dentigerous cys associated with an ectopic third molar in the maxillary sinus:
A case report and review of literature. Contemp Clin Dent [Internet]. 2012;3(3):373-6. Available from: http:// www.pubmedcentral.nih.gov/articlerender.fcgi? artid $=3532812 \&$ tool=pmcentrez $\&$ rendertype=abstract

5. Lilly-tariah OB, Upth ENTS, Harcourt P. Dentigerous cys associated with ectopic tooth at the roof of maxillary sinus. 2013;3(4):407-10.

6. Managutti A, Haidary N, Patel J, Patel P, Managutti S Dentigerous Cyst in The Maxillary Sinus Associated With An Ectopic Tooth : A Case Report. 2016;15(4):83-7.

7. Köse TE, Arsan B, Büyükertan M, Özcan I, Balcioğlu HA. Two Cases of Inverted Ectopic Teeth in Maxillary Sinus. 2016;1(3):3 -5 .

8. Beriat GK, Beriat NÇ, Esin Yalçınkaya. Ectopic Tooth in the Maxillary Sinus. Clin Dent Res. 2011;35(2):35-40.

9. Sinha A, Mishra A, Anusha, Sinha PM. ectopic third molar in Maxillary sinus: A rare case report. J Indian Acad Oral Med Radiol. 2017;29(4).

10. Sekiya K, Ishida M, Sekiya K, Suemitsu M, Hara Y, Kaneda T. Case Reports A Case of Impacted Tooth in the Maxillary Sinus : CT Findings. 2015;13(3):128-30.

11. Sushma P, Kumar MT. Incidental finding of dentigerous cyst -a case report. J Dent Spec [Internet]. 2015;3(2):183-7. Available from: http://its-jds.in/admin/uploadarticle/ Sep2015/1385494260.pdf

12. Farman alan G, editor. Panoramic Radiology. New York: Springer; 2007

13. So $E$, Özden M, Günbay T, Tugsel Z. Case Report Cone beam computed tomography findings of ectopic tooth in the maxillary sinus associated with dentigerous cyst : A report of two cases and review of the literature. 2015;3(2):70-5.

14. Hertog D, Bloemena E, Aartman I.H.A, Van Der Wal, I. Histopathology of ameloblastoma of the jaws; some critical observations based on a 40 years single institution experience. Journal section: Oral Medicine and Pathology.Publication Types: Research. Med Oral Patol Oral Cir Bucal. 2012 Jan 1;17 (1):e76-82.

15. Swati Deshmane, Ambika Arora, Deepa Das, Akansha Chaphekar, Komal Khot. Follicular Ameloblastoma: A Case Report. International Journal of Oral Health and Medical Research.2016: 3(4): 56-9

16. OA Effiom, OM Ogundana, AO Akinshipo, SO Akintoye. Histopathology of ameloblastoma of the jaws; some critical observations based on a 40 years single institution experience. Med Oral Patol Oral Cir Bucal. 2012 Jan 1;17 (1):e76-82. 